Revista Posgrado y Sociedad

Sistema de Estudios de Posgrado

Universidad Estatal a Distancia

ISSN 2215-2172

Costa Rica

revistaposgradoysoci@uned.ac.cr

\title{
Encontrar y decir al otro. Reflexiones en torno a la entrevista de personalidad
}

Meeting and Talking of others. Studies on Personal Interviews

\author{
Bértold Salas \\ Escuela de Estudios Generales \\ Universidad de Costa Rica \\ Volumen 11, Número 2 \\ Setiembre 2011 \\ pp. 16-39
}

Recibido: Febrero, 2011

Aprobado: Abril, 2011 


\title{
Resumen
}

Se reflexiona -desde el periodismo- sobre el quehacer periodístico, y específicamente sobre el género de la entrevista de personalidad, de perfil o semblanza periodística. Se consideran las dimensiones epistemológica y ética: primero, cuando el reportero se encuentra con el entrevistado, y segundo, cuando se enfrenta con el material y lo transforma en un producto periodístico.

Palabras clave: Periodismo, entrevista, epistemología, ética.

\begin{abstract}
The study reflects from the journalistic perspective the reporter's work specifically the personal profile or biographical interview. It considers epistemological and ethical aspects: first, when the reporter meets the subject, and second when he writes the story.
\end{abstract}

Keywords: Journalism, interview, epistemology, ethics. 


\section{Género con prestigio}

A la par del reportaje, la entrevista es uno de los llamados géneros periodísticos que goza de mayor prestigio. Entre los periodistas esto se origina, probablemente, en que ambos géneros comprenden mucho de lo que el periodista por lo general no puede hacer en su lugar de trabajo: tomarse su tiempo, observar las gentes y las cosas, descubrir nuevas fuentes $\mathrm{y}$ versiones, contrastar opiniones con las de sus colegas $y$, finalmente, verter un pequeño orden en este caos del mundo.

En el caso particular de la entrevista, además, esta cuenta con un importante valor simbólico, pues contribuye a reforzar la concepción del periodista respecto a su propio oficio como instrumento para la transformación social y política. Esto porque, finalmente, ¿qué es la entrevista, sino el enfrentamiento entre el hombre o la mujer públicos, con poder y responsabilidad, y el pequeño pero valiente reportero, voz inquisidora del pueblo? La anterior afirmación, por supuesto, hay que tomarla con guantes quirúrgicos $\mathrm{y}$ decirla con delicada ironía. A esto sumemos que, como ya fue indicado, la entrevista constituye una oportunidad única para el reportero: acostumbrado a atrapar en el aire datos $u$ opiniones, durante la entrevista tiene la oportunidad de "abrirse" a los gestos del otro, a sus contradicciones o, al menos, matices.

Por su parte, para el lector la entrevista también constituye una ocasión especial: la oportunidad de ver develado, de alguna manera, el rostro humano detrás de los hechos y los actos. En última instancia: lo que tienen en común esos político o deportista, artista o persona de la farándula con el resto de los mortales.

Un género con prestigio, tanto entre sus productores, los periodistas, como entre sus consumidores, los lectores, y que por tanto merece ser examinado. Examen que, como cualquier otro, requiere de alguna delimitación: por eso, antes de continuar y que esto se enrede un tanto - itanto como podamos!-, hay que advertir que existen entrevistas de entrevistas, y que entre ellas se explorará un tipo. En realidad, tres cuartas partes del quehacer periodístico consiste en entrevistas: pequeñas o medianas, sobre hechos puntuales o realizadas con la precisión de quien tantea en la oscuridad; los periodistas obtienen todo tipo de información a través de ellas, desde una estadística o la fecha de una actividad, hasta la explicación de un estudio o la reacción ante un hecho relevante.

En el caso de este artículo, el propósito es realizar una reflexión desde el periodismo sobre el quehacer periodístico -es decir: esto no es un texto sobre metodología o de análisis del discurso-, y acaso arrojar algunas luces sobre una de las formas de la entrevista: la llamada de personalidad, de perfil o, como se preferirá en este texto, la semblanza periodística. Esta es la entrevista que pretende descubrir no la participación de una persona en un hecho o su opinión sobre este, sino aprehenderla en su totalidad y complejidad de ser humano, mostrar su recorrido vital, 
sus aspiraciones y contradicciones..., si es que esto es posible en unas cuantas cuartillas.

Este texto considera dos dimensiones de la entrevista de personalidad: la epistemológica y la ética. En cuanto epistemológica, la investigación plantea las dificultades que hay para aprehender la otredad y después mostrarla en un texto periodístico; en tanto ética, revisa las implicaciones morales de esta aprehensión irremediablemente parcial. Del mismo modo, ambas formas de aproximación acompañan los dos momentos que se reconocen en la elaboración de la semblanza: primero, el antes y el durante de la entrevista, cuando el periodista y el personaje se encuentran; $y$ en segundo lugar, el después, cuando el periodista comienza la escritura del texto, su trabajo creativo - pero no por ello, menos artesanal-.

En un primer momento, estas eclécticas reflexiones parten de la propia experiencia profesional y de los manuales de periodismo. Pero a estas fuentes, se suma el rico material que brinda la bibliografía en técnicas de investigación cualitativa, especialmente las que versan sobre la entrevista de profundidad y las historias de vida (el llamado método biográfico). Cuando se citen fragmentos de esta procedencia, es porque se reconocen coincidencias con la entrevista periodística, al menos tal y como la conoce el periodista-investigador. Se aprovecha como ejemplo algún material proveniente de la literatura y del periodismo: semblanzas y entrevistas realizadas por Truman Capote, Oriana
Fallaci y Rosa Montero, así como por la costarricense Aurelia Dobles y el argentino radicado en Costa Rica, Ernesto Rivera.

Finalmente, una nueva demarcación: aunque algunas de las reflexiones son aplicables al periodismo radiofónico o televisivo, en general estarán dedicadas al periodismo escrito.

\section{Le llaman entrevista}

Como con la mayoría de los trabajos sobre el periodismo, estas reflexiones corren el peligro de entretenerse en lo obvio, en eso que todo periodista, o incluso lector, conoce, o al menos intuye. En el mejor de las cosas, en lo que de todos modos se encuentra en los manuales de periodismo o en los libros dedicados exclusivamente a la entrevista. Sin embargo, una de las reglas de oro del oficio periodístico es no dar las cosas por entendidas: en todo material informativo, antes de entrar en materia, siempre es pertinente una suerte de nivelación del conocimiento.

Para comenzar, hay que considerar que se suele llamar "entrevista" a dos procesos distintos, pero estrechamente unidos: por un lado, el acto de entrevistar, el encuentro entre entrevistador $y$ entrevistado; y después, el producto final, aquel que finalmente llega al lector como entrevista $-\mathrm{y}$ a veces, como semblanza-.

$\begin{array}{llr}\text { Para el primer caso, ese } \\ \text { encuentro entre } & \text { un } \\ \text { periodista/investigador y } & \text { una } \\ \text { fuente/sujeto, es interesante } & \text { esta }\end{array}$


descripción proveniente de la sociología: “(...) un intercambio verbal, que nos ayuda a reunir los datos durante un encuentro, de carácter privado y cordial, donde una persona se dirige a otra y cuenta su historia, da su versión de los hechos y responde a preguntas relacionadas con un tema específico" (Sierra, 282).

Sierra señala a los Diálogos platónicos como uno de los orígenes de la entrevista, y allí destaca la noción socrática de alcanzar el conocimiento por medio de la conversación (la mayéutica). Escarbando entre los conceptos que aporta esta definición, encontramos los elementos clave de la entrevista periodística, y en ella, de la semblanza. Estos son: el intercambio verbal; la recolección de datos; el encuentro entre dos personas, por lo menos, y en la cual cada una tiene roles diferenciados; de la oportunidad de hacer preguntas por parte de uno, y la importancia la "versión de los hechos" del otro.

También es Sierra quien recuerda que "entrevista" significa "entrever", "ver en medio" del otro (Sierra, 282). No forzamos la etimología al afirmar que la entrevista supone ver a la persona, a través pero sin salir de ella, en sus tres dimensiones, en sus altura y anchura, pero también en su profundidad, sin olvidar, más bien interesándose, por esas irregularidades o fisuras.

Por supuesto, la definición de Sierra no se ajusta enteramente a una de entrevista periodística: en primer lugar, porque en el periodismo el encuentro entre reportero y fuente no es necesariamente cordial y, más importante, porque tiene un carácter público. Aunque la entrevista no sea "publicada" en el momento de su realización -si es prensa escrita y no radio o televisión-, se supone que lo será temprano o tarde.

Por otra parte, desde la trinchera del periodismo, Halperín se ocupa de advertir que la entrevista es "la más pública de las conversaciones privadas" (Halperín, 13). Para comenzar, porque comparte características con el diálogo cotidiano y privado: proximidad entre los hablantes, intercambio de información, exposición discursiva con interrupciones, presencia de lo personal y, muy importante, atmósfera de intimidad; paradójicamente, todo esto construido en el ámbito de lo público. En tanto conversación pública, hay que destacar dos elementos en la entrevista: que los interlocutores representan explícitamente a determinadas instituciones -aunque el entrevistado lo sea de manera indirecta-; y que uno de los interlocutores, otra vez el periodista, está socialmente legitimado para hacer preguntas (Halperín, 14).

Como antes fue dicho, hay entrevistas de entrevistas: ya en las páginas de un diario o revista, la entrevista puede ser una entre varias en una nota informativa; puede ser la fuente de todo el artículo informativo; puede alimentar un reportaje o constituir una nota con cierta autonomía dentro de un paquete informativo; puede mostrarnos el criterio de alguna persona a quien las circunstancias convierten en figura. 
Además, la presentación de la entrevista es también diversa: puede no citarse al entrevistado; puede citarse con algún parafraseo o entre comillas dentro del texto, en medio de uno o varios párrafos informativos o interpretativos; puede dedicarse todo el artículo a la entrevista.

En el caso de que la entrevista sea el artículo, las opciones continúan desgranándose: es posible una presentación "pregunta-respuesta" al menos, así se conoce en Costa Rica-, según la cual a una pregunta del periodista sigue una respuesta del entrevistado; la otra opción es el "extracto" (excerpt), donde las declaraciones forman parte de una narración elaborada por el periodista. ¿Qué supone cada una? El formato de "pregunta-respuesta" aproxima al lector a la forma del diálogo original, le otorga verosimilitud al texto; pero generalmente no impide que el periodista haga algo más que preguntar y transcribir respuestas: edita, retoca frases, corrige las propias $\mathrm{y}$ ajenas torpezas verbales, incluso varía el que fue el orden de la conversación. Al contrario, el "extracto" gana en espacio para contextualizar las declaraciones del entrevistado, pero resulta menos "verosímil" para el lector: las palabras del personaje se leen con menos frecuencia, y es explícita una voz narrativa, que hace anotaciones y sin disimulo "invita" a otros sujetos o posibilita brincos temporales. Es pertinente destacar que en las dos formas hablamos de textos escritos; es decir, elaborados a partir de discriminaciones de carácter informativo y lingüístico..., si bien no es tan obvio en la entrevista de "pregunta-respuesta".

En cualquier caso, en la entrevista se persigue lo que Martínez Albertos resalta del género, y esto es que "posee una apariencia de calor humano propio, nacido de la sensación de inmediatez que se establece a través del recurso de las, en principio, propias y personales palabras del entrevistado" (Martínez Albertos, 109). Según interpreta el periodista español, la popularidad del género puede vincularse con que brinda a los lectores, miembros de una sociedad "tecnificada, muchas veces aplastante para el individuo", la oportunidad de "establecer una especie de corriente confidencial" con el protagonista de la noticia, "que cuenta sus cosas más o menos íntimas" (Martínez Albertos, 109). Esta oportunidad se ve aumentada en la semblanza periodística, puesto que su objetivo es "captar el carácter, las costumbres, el modo de pensar, los datos biográficos y las anécdotas de un personaje" (Leñero y Marín, 98).

\subsection{El encuentro}

En sus respectivos estudios sobre la entrevista, Halperín y Sánchez regalan dos interesantes caracterizaciones de la entrevista; el primero afirma que es "el arte del vínculo" (Halperín, 24); por su parte, el segundo agrega que este arte consiste en saber mirar, saber escuchar, saber pensar y saber expresar (Sánchez, 16). Desmenuzando: la primera idea apunta a que la entrevista parte y depende de la interacción que logren el periodista y la persona 
entrevistada; a esto se llama rapport. En cuanto a los distintos saberes mencionados por Sánchez, estos resaltan la concentración del comunicador pendiente del más mínimo detalle. Dicho de manera poco amigable: apenas al comenzar este recorrido por el hacer de la semblanza, surge la primera dificultad: es necesario generar una atmósfera cordial, acaso relajada, pero sin atentar contra la actitud alerta, casi paranoica, que en su fuero interior ha de asumir el entrevistador, pendiente de las pequeñas cosas, de una cita-citable o frase-título.

Esto de no descuidar detalle, ir dirigiendo la conversación y lucir la mar de tranquilos, es una dificultad, principalmente para los periodistas con poca experiencia, aunque también pone en aprietos a cualquier veterano, sin importar el currículo. Cuando se muestra nervioso, en el mejor de los casos, el periodista queda como un inexperto o poco preparado para la entrevista; en el peor, genera desconfianza en la fuente y desde allí, apenas hay que mal andar un paso para que alguien termine irritado, el que pregunta o el que responde, o ambos.

En toda entrevista, y acaso especialmente en las del tipo que estudia este artículo, el encuentro entre periodista y fuente requiere de la existencia de una serie de condiciones idóneas; de lo contrario, se corre el riesgo de que surja una serie de problemas, tanto éticos como epistemológicos. Una cita con el protagonista de una semblanza requiere de las mejores circunstancias en cuanto a tiempo y lugar; es decir: ni prisa ni incomodidades. Y no sobra destacar que es mejor ser puntual, para no generar un desgaste innecesario en la relación con la fuente.

Según la experiencia del investigador, uno de los aspectos que descuidan los periodistas costarricenses es la documentación respecto al entrevistado. Muchas veces, esperan que este les cuente su vida, precise fechas y oficios, desperdiciando tiempo valioso $-\mathrm{y}$ después espacio en el texto escritoque puede dedicarse a conocer qué hay detrás de toda esa información curricular. Antes de la entrevista, y con alguna investigación previa, el reportero puede conocer desde el nombre completo y una sintética biografía, hasta algunas nociones respecto a su carácter, gustos, aficiones: si es un escritor, qué ha escrito; si es un intelectual o un tecnócrata, qué ha investigado o puesto en ejecución; si es un político, cuáles ha sido su filiación, su trayectoria, sus amigos y sus enemigos. Cornelius Ryan recomendaba: "nunca entrevistes a alguien sin conocer el 6o\% de sus respuestas" (citado en Halperín, 63).

Volviendo al rapport, entrevistar supone encontrarse con los inestables materiales de la conciencia y la conducta humana; de allí, el indispensable estado de alerta. Según lo afirma Halperín, en su fase de "trabajo de campo" la entrevista: “...pertenece al reino del instante, y el entrevistador debe adquirir maestría en las leyes que gobiernan su curso: lo efimero y lo banal entremezclado con lo profundo, la dispersión, el 
juicio terminante y muchas veces arbitrario, los cambios de ritmo, el mutuo semblanteo, los juegos de manipulación y de ocultamiento, la confidencia, las puestas en escena" (Halperín, 109). Una parte importante de esta fase de la semblanza depende de la buena química entre reportero y fuente. García Márquez aseguró que "las entrevistas son como el amor: se necesitan por lo menos dos personas para hacerlas, $y$ solo saben bien si esas dos personas se quieren"; si esto no resulta, "el resultado será un sartal de preguntas y respuestas de las cuales puede salir un hijo en el peor de los casos, pero jamás saldrá un buen recuerdo" (citado en Leñero y Marín, 119). En un sentido análogo, Sierra recomienda la empatía como "recurso cognoscitivo para la entrevista"; esta es la capacidad de comprender lo narrado desde la perspectiva del entrevistado (Sierra, 291).

No tiene que pensarse que esta química o empatía es un simulacro que lleva a cabo el periodista. Por el contrario, generalmente el periodista logra una sincera familiaridad con sus fuentes y su historia personal, y puede pasar de la empatía a la simpatía, en especial si les sigue la pista por un tiempo prolongado. Entonces, disminuye el problema epistemológico, de conocimiento del otro, pero surge uno ético: que al entrevistar o escribir, el periodista piense más en el sujeto, su amigo, que en sus lectores. Esta idea será retomada más adelante.

Es probable que entre las formas periodísticas, la semblanza sea la que más depende del viejo arte de la conversación. Si se falla en el establecimiento del vínculo, si la comunicación se ve plagada de distorsiones, es difícil obtener información de primera mano. Entonces, para retratar al protagonista de nuestra semblanza hay que recurrir a fuentes secundarias: la documentación obtenida, los colegas o amigos con quienes es posible hablar; sin embargo, es información menos "próxima" y por esto menos fiable que la que nos daría el personaje, además de que no permite repreguntas o demasiadas precisiones.

\subsection{Ardiente paciencia}

En este encuentro entre dos o más personas -casi siempre desconocidas-, lo mejor es comenzar con cuestiones agradables, las cuales contribuirán a disminuir o eliminar la tensión. Por supuesto, esto no siempre es posible, no siempre hay espacio para preguntas lubricantes: nuestra fuente puede pasarlo muy ocupada, y la cita tiene que desarrollarse en medio de otras dos reuniones. No es la circunstancia idónea, porque: ¿cómo escarbar en una persona, si las preguntas y respuestas han de surcar el aire como mísiles, en el lapso de unos minutos? Por otra parte, esta urgencia del personaje también es aprovechable: nos dice mucho de su vida, como también las incomodidades del mobiliario o los ruidos que dificultan la conversación pueden enriquecer la escritura de la semblanza. Sin que sean exactamente semblanzas aunque están dedicadas a escarbar en 
un personaje-, un ejemplo de estas posibilidades eran las entrevistas en la sección Domingo siete, del suplemento cultural de La Nación, donde la periodista Aurelia Dobles se encontraba con personalidades de la cultura y la política costarricense en lugares insólitos (un sauna, un salón de baile, un edificio a medio hacer), buscando una interacción vital y conceptual entre el sujeto y el contexto. Pero nuevamente, no son las circunstancias idóneas.

Asimismo, aunque al protagonista de la semblanza puede perdonársele poca disposición y falta de tiempo, estas consideraciones no las tiene el reportero para sí. En primer lugar, porque el entrevistado puede percibir esta prisa y esto determinará su actitud y respuestas. Además, porque el periodista puede verse cortando las ramitas que apenas surgen del tronco de la conversación, sin dejarlas crecer y descubrir hacia adonde se dirigen: es decir, caer en un excesivo direccionismo y perjudicar la "fiabilidad" de la entrevista (Pujadas, 46).

La utilización de un guión de trabajo es recomendada, pero con mesura. Es decir, generalmente es mejor que el encuentro consista en un "caos administrado por el entrevistador" (Halperín, 99), pues de esta manera se propicia la espontaneidad de la fuente en sus declaraciones. Es decir: que la conversación tenga una apariencia caótica para el personaje, o para un testigo, pero no para el periodista, quien sí sabe con cierta certeza qué es lo que quiere. No debe maniatar la conversación, pero sí focalizarla de previo.

Como antes fue apuntado, en este guión lo más recomendable es seguir "la lógica del embudo", de la soga gruesa al hilo fino, de las preguntas cómodas a las de examen para probar la "resistencia" del otro-, y de estas a las ordinarias, cada vez más difíciles. Sin ser inhumano, el periodista requiere de la frialdad del verdugo para ir dosificando las preguntas y lucir siempre cordial y seguro de sí; en este sentido, es interesante la recomendación a un joven periodista por parte del actor Humphrey Bogart: "Provoque agujeritos con las entrevistas. La mejor técnica consiste en provocar pequeños pinchazos en el ego del sujeto y dejar que exhale lentamente aire caliente. No avance perforando la arteria principal. Con eso solo conseguirá provocar su hostilidad. No es caballeresco ni lúcido" (citado en Halperín, 110). La tarea consiste en que el otro hable, no tanto que conteste. Dicho de otra manera: que el entrevistado baje sus defensas, sin que lo haga también el periodista.

Cuando la entrevista se realiza a una persona dedicada al trabajo intelectual, por ejemplo un académico, es frecuente que desconfíe de ese periodista como lo haría de cualquier estudiante de primer año. Nuevamente, la recomendación es no partir de sobreentendidos: la comunicación se ve afectada si no se toma en cuenta el ámbito sociocultural, pues "las palabras y los gestos con frecuencia se interpretan en un sentido distinto" (Sierra, 285), y así también ocurre con los lenguajes 
especializados. No siempre es posible, pero lo más recomendable es tomarse el tiempo: saborear las respuestas, estar pendiente de los cabos sueltos, mostrar firmeza para repreguntar algo que no está claro o que se descubre como pasado por alto deliberadamente. $\mathrm{Y}$ ya que la semblanza es la pretensión de dibujar por entero a una persona, es muy pertinente recordar lo que el escritor francés André Gide dijo a un periodista: "No me entiendas demasiado rápido" (citada en Halperín, 118). En cualquier caso: "descubrir al otro" -y sin prisa- es una de las mayores satisfacciones que brinda la vida.

Para hacer una semblanza, los periodistas han de tomar en cuenta que son posibles personajes interesantes, dispuestos a una entrevista, pero difíciles como personas, incluso extravagantes. Este era el caso de Vladimir Nabokov, quien aceptaba atender a los periodistas, pero por escrito porque: "Pienso como un genio, escribo como un autor notable y hablo como un niño", según decía (citado en Halperín, 156). Entrevistarlo debió de ser inolvidable: Nabokov escuchaba la pregunta, meditaba su respuesta y de pie, sobre un atril, la escribía. En circunstancias como esta o similares, es decir con gente difícil, resulta peligroso tomar como único material para una semblanza el material recogido durante el encuentro; en un sentido semejante Rosa Montero, periodista y autora de semblanzas de personajes históricos (Historias de mujeres, Pasiones), hacía esta advertencia con reminiscencias socráticas y que parece resumir el presente artículo: "no te conoces ni a ti mismo, no vas a conocer a alguien en dos o tres horas".

\subsection{Un par de seres humanos}

Salvo que el personaje sea especialmente cándido, siempre tendrá presente que detrás del periodista hay un medio informativo, una ideología y un tipo de lector, entre otras cosas, y esto condicionará sus preguntas (Halperín, 14). Además, el entrevistado recuerda a potenciales pero específicos lectores: su familia y amigos, sus colegas, sus jefes, sus rivales intelectuales o políticos, si los hubiera. Además, hay gente experimentada -entrevistados muchas veces-, que muy pronto descubren nuestra estrategia de diálogo, como también otros con especial agudeza o desconfianza, que cierran muy pronto las puertas hacia ciertos temas. ¿Cómo entrar allí? Nuevamente, si el periodista no logra una atmósfera cordial, es muy difícil que el otro baje sus defensas; por esto, las intervenciones del periodista tienen que ser muy bien pensadas: como en toda conversación surgen tensiones con consecuencias epistemológicas, pues distorsionan el acceso a la información por parte del periodista. Por ejemplo, expresar opiniones repercutirá en el discurso del entrevistado, especialmente si son contrarias a sus opiniones; pueden llevarlo a redundar sobre cosas ya dichas, o modificar sus opiniones para "agradar" al periodista.

Tan interesante como que el entrevistado oye al periodista preguntar, es que se escucha a sí 
mismo responder: durante el encuentro, el sujeto relata, explica y hasta justifica su vida ante nosotros, y ante sí mismo. Rehace su vida, se narra. Recordemos que la etimología de persona remite a máscara: la personalidad es la careta que nos ponemos, un rol que se cumple o un papel que se interpreta en la sociedad. Tampoco puede desconocerse lo que hay de voyeurismo en el periodista o en el probable lector, que pretende entrever en esa máscara, y de exhibicionismo en el entrevistado (Sierra, 325), que quiere mostrar unas cosas, pero otras no. Si es perspicaz, todos estos elementos dicen mucho al periodista sobre el quien de la noticia, sobre el protagonista de la semblanza; el riesgo es malinterpretarlos, o no ponerlos claramente en su artículo.

Un ejemplo de la entrevista como oportunidad de "justificación" es El duque en sus dominios, probablemente la más conocida de las semblanzas escrita por Truman Capote, dedicada a un Marlon Brando en el apogeo de su carrera. En ella, Brando afirma que su carácter no es el grosero y volcánico de Kowalski, el personaje de Un tranvía llamado deseo, filme que lo lanzó a la fama; al contrario, durante la velada en que ocurrió la entrevista, insistió sobre sus aspiraciones humanitarias, así como respecto a su sensibilidad e inseguridad frente "al otro", hasta el punto de afirmar que "Puedo entrar en una habitación donde hay cien personas, $y$ si hay una sola que no me quiere, me doy cuenta, y siento la necesidad de irme" (Capote, 56). Verdades o mentiras, estas declaraciones permitían a Brando forjar una nueva imagen frente a su público, y lograr la simpatía de Capote. Y es que como en toda conversación, en la entrevista hay un proceso de seducción: para ganarse al periodista y acaso convencerse a sí mismo, Brando y cualquier entrevistado recurre a "una amplia gama de estrategias de discurso, de movimientos, de trucos conversacionales”(Alonso, 233).

\subsection{Esos trucos}

Así como el entrevistado tiene sus trucos, sus maneras de decir o no las cosas, en el oficio periodístico se han pulido argucias para contrarrestarlos: contar anécdotas, para que el otro asuma el reto de contar una mejor; guardar silencio y mantener la mirada firme después de una respuesta insatisfactoria, para que el otro sienta que debe decir más; mencionar datos con alguna imprecisión, para que el entrevistado corrija y detalle.

Pero las mayores sutilezas son posibles cuando se conoce previamente al entrevistado..., y de él, su carácter y ego: de esta manera, surgen las preguntas que son irresistibles si el otro no percibe sus riesgos. Un ejemplo célebre es la que hizo Oriana Fallaci a Henry Kissinger: era el final de la entrevista, y la periodista italiana preguntó al diplomático cómo podía ser "casi más famoso y popular" que su jefe y presidente, Richard Nixon. Aunque al principio mostró cierta resistencia -a sí mismo, principalmente-, finalmente respondió que a los estadounidenses les gustaba "el hecho de haber actuado siempre solo (...) El 
cowboy que entra solo en la ciudad, en el poblado, con su caballo y nada más" (Fallaci, 33). Henry Kissinger viéndose como Henry Fonda...: la imagen se prestó para más de una caricatura del diplomático con traje de vaquero; sin embargo, lo más difícil para él fue que la respuesta tan vanidosa molestó al resto del gabinete norteamericano, incluido al presidente Nixon, porque eso de "haber actuado siempre solo" era desconocer que lo hacía según sus órdenes.

En ocasiones, los trucos rozan y acaso rebasan los límites éticos..., por ejemplo: ¿es válida una mentira, o una verdad a medias, para obtener una declaración? Una parte importante del reporteo que realizaron Woodward y Bernstein fundamental en el destape del escándalo de Watergate-, fue posible porque estos periodistas recurrieron a mentiras durante sus entrevistas: por ejemplo, según relatan en Todos los hombres del presidente, visitaban a una empleada del Partido Republicano y le decían que uno de sus compañeros les habló de ella como una persona que quería hablar; esa primera persona no existía, pero efectivamente la mujer tenía algunas cosas que decir. ¿Son válidos trucos como este? ¿Y en una semblanza? Desde este análisis: lo mejor es no mentir, ni servirse de medias verdades; en realidad, por lo general no es necesario hacerlo. Sin embargo, si se miente o no se dice toda la verdad, es un requisito del texto diga lo correcto, haga evidente esa estratagema y explique por qué el periodista debió utilizarla, para que el público juzgue.

También en El duque en sus dominios, Capote muestra otro triunfo de la astucia: durante toda la noche, el autor de $A$ sangre fría contó a Brando la historia de su relación con una madre alcohólica. Conmovido, el actor habló del comportamiento similar de su madre: de la casa sola cuando regresaba de la secundaria, y las llamadas desde un bar, pidiendo que la recogieran. Por supuesto, en la semblanza publicada aparecieron los recuerdos de Brando, no los de Capote; el primero se molestó, pero según el segundo, repetidas veces durante el encuentro le recordó que todo lo dicho podía ser publicado.

Las diferencias entre escritor y actor tras la publicación de El duque en sus dominios, permiten introducir la noción del "contrato comunicativo". El contrato es un compromiso que marca la relación entre entrevistador y entrevistado, determina sus conductas (Alonso, 231) y contribuye a focalizar los temas de la interacción (Alonso, 233). En el caso periodístico, este acuerdo va desde cuestiones implícitas, como las instituciones que están representadas por los participantes o los saberes mínimos, hasta otras que son explicitadas, como las partes del diálogo que permanecerán off the record, los temas que es preferible no tocar o la intervención de la fuente en la escritura del texto.

Alonso aconseja hacer evidentes los términos del contrato comunicativo en las entrevistas de ciencias sociales, como una herramienta para disminuir la 
tensión. Con sutileza, sería provechoso aplicar esta recomendación en la prensa, donde la relación entre reportero y fuente está cargada de "no dichos"; probablemente, más de un malentendido se evitaría si se revisa que las cartas no están marcadas antes del comienzo de la partida.

\subsection{Prejuicios}

En el oficio periodístico, la epistemología y la ética son dos caras de la misma moneda, inseparables, de pronto intercambiables dentro del análisis. Una dificultad epistemológica, para obtener información, tiene consecuencias éticas, pues dificulta el cumplimiento del papel que la sociedad atribuye al periodismo; también viceversa: un sesgo ético, como un prejuicio, puede cegar al reportero, impedir que vea al entrevistado, y así repercutir negativamente en lo epistemológico, que es la obtención de información.

Los prejuicios pueden surgir a partir del inevitable roce de los propios valores con el conocimiento previo que se tiene del entrevistado, de las instituciones que representa, o de la información recogida por el periodista como parte de su preparación. Y decir inevitable no es gratuito: la toma de posición es inherente a cualquier aproximación a la otredad, si bien lo ideal es que esta postura sea flexible, permeable a nuevas perspectivas. Según recomiendan Sánchez, Halperín y Leñero y Marín en sus respectivos libros, lo mejor es acercarse al entrevistado con afán de saber, con la mente abierta. Otra vez: esto no significa desprenderse de valores o prejuicios, o peor aún, fingir hacerlo - pues lo primero es imposible-; lo más recomendable es reconocerlos para sí y, si es necesario, hacerlos explícitos durante el encuentro con el entrevistado a través de las preguntas y escasos pero concretos comentarios; la misma posición debe quedar registrada en el texto de la semblanza.

Justo acá reaparece la figura de Oriana Fallacci, quien introduce su colección Entrevista con la historia con la tajante afirmación de que "Yo no me siento, ni lograré jamás sentirme, un frío registrador de lo que escucho y veo", y agrega que en toda experiencia profesional "dejo jirones del alma, participo con aquel a quien escucho y veo como si la cosa me afectase personalmente o hubiese de tomar posición ( $y$, en efecto, la tomo, siempre, a base de una precisa selección moral)" (Fallaci, 9). Ciertamente, sus famosas entrevistas eran los encuentros de una periodista casi anarquista, al menos libertaria e insolente, con personajes que detentan el poder, con el propósito de descubrir "en qué son distintos de nosotros" (Fallaci, 11).

Otro peligro, ya advertido, radica no en una actitud agresiva o prejuiciosa contra el entrevistado, sino a favor: el creer que entre éste y el periodista hay muchas cosas en común. $Y$ es que al mismo tiempo que el carácter tóxico de los entrevistados -ese excesivo carisma que puede conquistarnos-, los periodistas pueden creer que por codearse cotidianamente con autoridades o personajes públicos, son "uno de ellos". 
Un riesgo bastante similar es que de la simpatía se pase a la empatía, y después a la identificación; si ocurre, el periodista tiene que reconocer el fenómeno, y mostrarlo sin reparos en el texto; nuevamente, para que el lector juzgue. Otra vez con la Fallaci, cuando entrevistó a jefas de estado como Golda Meir o Indira Gandhi, la admiración e incluso el cariño hacia ellas fueron parte del material entregado al público. Al referirse a Meir, la compara varias veces con su propia madre; y en los dos casos, destacó la imposibilidad de una feliz vida privada para las mujeres que optan por ser figuras públicas..., como ella misma. Este tipo de relaciones entre entrevistado $y$ entrevistador tienen sus implicaciones éticas: el retrato tan favorable de Meir era de alguna manera inclinarse a favor de las operaciones de su gobierno contra los palestinos, y el de Gandhi resultó un bofetón contra Pakistán.

La misma Fallaci advierte sobre estos peligros en otro pasaje de Entrevista con la historia, cuando cita al periodista norteamericano Walter Cronkite, quien como ella entrevistó a muchas personas con poder, algunas responsables de actos atroces. El periodista aseguraba que "no se puede juzgar a un jefe de Estado viendo en él solo al hombre". ¿Por qué? "Pues en cuanto descubres que también es solo un hombre, con las virtudes, defectos e incoherencias del hombre, inevitablemente te gusta y olvidas lo demás" (Fallaci, 201).

\subsection{Confrontación}

Autores como Escobar entienden la entrevista como una confrontación: "La entrevista supone un juego de ataque y defensa que puede llegar a la hostilidad, para que las preguntas, en el acecho, obliguen al autorretrato" (Escobar, 89) y un poco después agrega que las "buenas entrevistas se logran, por lo general, cuando el periodista sabe tanto o más que el entrevistado del tema que se va a tratar, para poder contradecirlo, provocarlo" (Escobar, 92). A esta caracterización pueden hacerse al menos tres objeciones epistemológicas, y una de ellas desde la perspectiva específica de quien escribe una semblanza. La primera es el tono de ciertas palabras (ataque, hostilidad, acecho, contradecir, provocar), que no son aplicables a la mayoría de las entrevistas; sin embargo, podría concederse que lo que pasa es que la mayoría de las entrevistas se "hacen mal", y el tono preferible es el recomendado por Escobar. La segunda: esta posición no es la mejor para los periodistas con poca experiencia, o para aquellos cuya capacidad dialéctica no es muy rápida: existen personalidades extremadamente hábiles para argumentar, que saben cómo ganar una discusión..., en caso de que pensemos que la entrevista consista en eso, en ganar, y no en obtener el mejor testimonio. $\mathrm{Y}$ en cuanto a la semblanza, hay que considerar que el encuentro con la fuente es la oportunidad de obtener 
información de primera mano, así que la cordialidad es una manera de que el otro se abra y brinde información; por supuesto, esto no impide repreguntar o cuestionar sus argumentos.

Sin duda, lo que propone Escobar es pertinente en algunas entrevistas y para cierto tipo de fuentes: políticos, autoridades, figuras públicas cuestionadas, gente cuyo lugar en la sociedad incluye el continuo escrutinio público. En otros casos, es una apuesta riesgosa para lograr las mejores respuestas por parte del entrevistado: en su afán de lucimiento el periodista puede llegar a cometer injusticias, como atacar a quien no corresponde, o caer en el ridículo, si el entrevistado es más hábil que él.

En la actitud agresiva propuesta por Escobar, se encuentran claras reminiscencias de las entrevistas realizadas por Fallaci a políticos de todo el mundo durante los 60 y 70. $\mathrm{Y}$ respecto a estas -pese a su innegable brillantez inquisitiva-, resulta válida la crítica que hace el narrador de La inmortalidad, de Milán Kundera. En esta novela, un capítulo está dedicado a recordar así los encuentros de la Fallaci con líderes como Indira Gandhi, Yasser Arafat o el citado Kissinger: "Aquellas conversaciones eran algo más que simples conversaciones; eran duelos" y agrega que los entrevistados "antes de advertir que se estaban batiendo en condiciones desiguales -porque las preguntas podía hacerlas ella y ellos no- ya se retorcían K.O. sobre la lona del ring”. El narrador no elogia la pericia de Fallaci, sino que cuestiona su papel, y el de la prensa en el mundo contemporáneo, con argumentos éticos y, si se quiere, ontológicos: para comenzar, el periodista no es el que pregunta, sino "aquel que tiene el sagrado derecho de preguntar, de preguntarle a quien sea lo que sea (...) el poder del periodista no está basado en el derecho a preguntar, sino en el derecho a exigir respuestas" (Kundera, 131). En La inmortalidad, los abusos que cometen los periodistas responden a lo que llama el "undécimo mandamiento", y tienen por triste característica que "la verdad (...) no se refiere ni a la fe ni al pensamiento, es una verdad de la planta baja de la ontología, la verdad puramente positivista de los hechos" (Kundera, 132). Dicho de otra manera: las respuestas que exige el periodista no apuntan a una comprensión del mundo, sino al detalle vulgar, carente de sutilezas, cuantificable, simplista.

\section{La escritura}

En los manuales, las escuelas de periodismo $\mathrm{y}$ en los medios informativos costarricenses, es frecuente considerar que respecto al reporteo, la etapa de escritura es menos importante e incluso menos exigente en cuanto esfuerzo. Puede ser: los periodistas trabajamos a 
partir de la información recopilada, y sin duda es más valioso un par de buenos datos o declaraciones, que una entrada digna de García Márquez, una metáfora a lo Borges o un juego de palabras que envidiaría Umbral. Sin embargo -y especialmente con la semblanza-, también la redacción requiere de cuidados: en primer lugar, para organizar la información y brindar contundencia al material recogido. Asimismo, y por estar más cerca de esa última estación que es el público lector, esta etapa tiene más implicaciones éticas que el encuentro con la fuente: frente al periodista, ya no hay un otro corpóreo, lo único que se le opone es una pantalla o página en blanco. Queda la sombra del otroentrevistado, pero dibujada en unas notas, en alguna grabación. Incluso de quienes serán los destinatarios de la semblanza, el periodista tiene una idea bastante borrosa: algo sabe de los lectores de su diario o revista, pero de manera general. Es decir, en materia ética, durante la escritura el periodista está solo... Con su conciencia.

La primera dificultad que surge es la del traslado de las respuestas del entrevistado, generalmente verbales, a un soporte escrito. En algunos casos, supone transformar un lenguaje ordinario a reflexiones de mayor alcance; en otros, convertir una observación técnica, o al menos compleja, en un vocabulario que pueda entender la mayor cantidad de gente. Es probable que haya mucha información, tanto proveniente de la entrevista al personaje, como recogida en otras fuentes. Sea dicho con énfasis: hacer un retrato integral va contra la fácil opción de encapsular al sujeto en unos cuantos datos que, justamente por precisos (cuándo nació, dónde estudió, qué cargos ha ocupado), son insuficientes. Como ya fue mencionado, la semblanza apunta al "quién" de la noticia, y para aproximarse realmente a este hay que recurrir a fórmulas alternativas: el juego de palabras, la analogía, la metáfora. La dificultad, epistemológica y ética, es que esa figura literaria, ese rodeo por los bordes del otro, sea algo más que un logro estilístico -más que el placer que siempre hay en conseguir una imagen única-: tiene que ser un camino para la expresión de la otredad aprehendida.

\subsection{Entrar y salir}

La semblanza se aleja del artículo noticioso: la cotidianidad de pocas personas depende de su lectura. $\mathrm{Su}$ propósito es, más bien, lúdico: quiere ser una buena lectura. Es decir: una semblanza busca ser atractiva para el lector, y lo menos atrayente es comenzar una semblanza con un lead clásico. Al contrario, la entrada de una semblanza busca no informar, sino "ganar la atención del público, excitar su curiosidad, interesarlo en el escrito, invitarlo a seguir toda la entrevista" (Leñero y 
Marín, 142). Desde sus primeras líneas, el texto marca una ruptura con respecto al artículo periodístico convencional: un tema y énfasis distintos, multitud de fuentes, vocabulario más sofisticado, por lo general una longitud mayor.

Asimismo, el cierre de la semblanza tampoco es convencional: no es lo menos importante, sino información que ponga en perspectiva lo leído, como podrían ser una valoración del personaje, una declaración pintoresca, una frase que recuerde la entrada (Leñero y Marín, 152). En cualquiera de los casos, brilla con luz propia la creatividad del periodista, así como su conocimiento del ritmo literario, por lo que hay de armonía de ideas y sonidos en un texto bien escrito.

Entrar y salir de un relato puede hacerse de muchas maneras, y en cada caso con distintas intenciones y consecuencias. A manera de ejemplo, se presentan fragmentos de tres entrevistas aparecidas en la prensa nacional e internacional. Para comenzar, una entrevista que ya ha sido mencionada en este artículo: la realizada a Henry Kissinger por Oriana Fallaci, que más de treinta años después aún puede leerse con admiración: "Este hombre tan famoso, tan importante, tan afortunado, a quien llamaban Superman, Superstar, Superkraut, que lograba paradójicas alianzas y conseguía acuerdos imposibles, tenía al mundo con el alma en vilo, como si el mundo fuese su alumnado de Harvard. Este hombre increíble, inescrutable, absurdo en el fondo, que se encontraba con Mao Tse-tung cuando quería, entraba en el Kremlin cuando le parecía, despertaba al presidente de los Estados Unidos y entraba en su habitación cuando lo creía oportuno, este cuarentón con gafas ante el cual James Bond queda convertido en una ficción sin alicientes, que no dispara, que no da puñetazos, no salta del automóvil en marcha, pero aconsejaba guerras, terminaba guerras, pretendía cambiar nuestro destino e incluso lo cambiaba. En resumen, ¿quién es Henry Kissinger?”(Fallaci, 15).

Evidentemente, y en contra de lo que recomiendan los manuales para una nota informativa, Fallaci comienza con una inmensa interrogante. Un arranque que está colmado de información, pues nos dice que el entrevistado es profesor, que tiene poder, que luce inescrutable..., pero que todos esos adjetivos no lo capturan, no llegan hasta él, el famoso Henry Kissinger. Este es el gancho: la entrada transmite la dificultad de comprender a un hombre poderoso $\mathrm{y}$, más importante, recuerda que es importante comprenderlo. A partir de entonces el texto, con un largo prólogo de Fallaci y después una típica entrevista preguntarespuesta, muestra las tentativas periodísticas por descubrir su historia, sus motivos y opiniones. 
El cierre vuelve a la entrada, pero esta vez a través de las palabras del mismo Kissinger: "-Comprendo, doctor Kissinger. Nunca he entrevistado a nadie que sortease como usted las preguntas $y$ las definiciones exactas, nadie que se defienda como usted ante la tentativa de penetrar en su personalidad. ¿Es usted tímido, doctor Kissinger? / - Sí. Bastante. Pero, en compensación, creo ser equilibrado. Hay quien me pinta como un personaje atormentado, misterioso, y quien me pinta como un tipo casi alegre que sonríe siempre, que ríe siempre. Las dos imágenes son inexactas. No soy ni uno ni otro. Soy... No le diré qué soy. No se lo diré jamás a nadie" (Fallaci, 35; énfasis del investigador). Para el lector, es imposible conocer si esta fue la última pregunta de la entrevista que fue realizada: solo puede saber que es la última presentada. Tampoco es posible verificar si la pregunta de Fallaci contenía tantos elementos vinculados a la "entrada" antes vista; lo más probable es que no, que la periodista haya agregado algunos para fortalecer el cierre. Estas son dos de las licencias del reportero: reacomodar el orden de las respuestas, sin sacar de contexto, para brindar mayor contundencia al material; y retocar las preguntas, para que se encadenen mejor los temas y brindar al lector más claridad en la exposición. Otra vez: son reacomodos pensando en el lector, no en el lucimiento del periodista.
De lo que debe tener certeza el lector es que Kissinger sí dio esta respuesta.

Después que Fallaci, durante los años 70 y 80, la ya mencionada Rosa Montero se especializó en entrevistas a personalidades provenientes de todo el espectro noticioso. Pero además, en la última de estas décadas, publicó en el diario El País semblanzas de personajes históricos que después fueron ampliadas y recogidas en sus libros Historias de mujeres y Pasiones. Si bien estas semblanzas no se alimentaban de entrevistas los personajes estaban muertos-, el principio era el mismo: aproximarse al otro, descubrir algún orden en el caos de sus vidas, encontrar cosas que pudieran ser dichas con certeza. Como material, Montero tenía sus obras literarias o artísticas, biografías y memorias, recuerdos de sus conocidos y una mente lo suficientemente aguda para ubicarse en una época distinta a la suya, y para comprender, en Historias de mujeres, el hecho de ser mujer, y en Pasiones, el amar en el mundo occidental.

De acuerdo con el lector que escribe estas líneas, entre estas semblanzas una de las más logradas es Voluntad de ser, dedicada a Simone de Beauvoir. Allí, la entrada y el cierre no muestran la incertidumbre de la entrevista a Kissinger, pero como ésta son ejemplares por la información que brindan y por la sencillez y el brillo estilísticos. Así comienza: "Una de sus jóvenes 
amantes, Nathalie, dijo de ella que era como un reloj dentro de una nevera. Natalie se sentía despechada porque Simone de Beauvoir no le daba todo el amor que ella pedía, pero aún así se diría que atinó con el símil. Simona, el Castor, la inmensa Simona que gravitó sobre generaciones de mujeres con su rotundo ejemplo de fuerza $e$ independencia, era al parecer así en su vida privada: laboriosa, precisa, congelada. Implacable en la construcción de su vida y en su relación con los demás" (Montero, 87)

¿Qué dice Montero de la imprescindible Simone de Beauvoir? Dice de su homosexualidad, frialdad, laboriosidad e importancia para el feminismo del siglo XX. Recuerda el sobrenombre que, por su laboriosidad, con afecto y respeto, le destinó Jean-Paul Sartre: Castor. Y recalca algo que descubrió en su investigación: que en su terca independencia intelectual y vital, la vida de Beauvoir fue una incansable lucha por construirse a sí misma; esta es la línea que Montero desarrolla a través de una docena de páginas, que son rematadas con las siguientes frases: " $Y$ al final, entre tanta gloria $y$ tanta miseria, lo que queda es la magnífica proeza de haber sido libre y responsable de su propio destino. Para bien y para mal, Beauvoir se hizo a sí misma" (Montero, 100). Con este "para bien y para mal”, la periodista vuelve a insinuar algo que también se lee entre líneas en la entrada y durante todo el texto: que el personaje de Beauvoir no le resultó completamente simpático; al contrario, le chocó esa voluntad de ser que rozaba lo artificial. Pero esta "falta de química", que vemos como posible hasta con un personaje ya fallecido, no impide a Montero buscar una explicación para su vida, y presentarla de manera que el lector juzgue.

Finalmente, para concluir con esto de las entradas y las salidas, se trae a colación la semblanza Un candidato con dos cabezas, de Ernesto Rivera, y dedicada a Óscar Arias en un número especial sobre los candidatos presidenciales de la campaña del 2006: "Al filo de la una de la tarde, la orquesta Kringkasting interpretó el último compás y el presidente del Comité del Premio Nobel, Egil Aarvik, anunció su nombre. Óscar Arias se tocó la cabeza en un gesto involuntario, como de quien se acomoda el cabello. Se puso de pie y devoró la distancia que lo separaba de aquel sueco de pelo gris y gafas de montura negra que le entregaría una medalla de oro con la cara del hombre que inventó la dinamita, y un cheque por $\$ 330.000$. Era el 10 de diciembre de 1987, desde el auditorio lo observaba el rey de Suecia, Orlav $V$, el excanciller alemán Willy Brandt, $y$ el controversial expresidente de Venezuela, Carlos Andrés Pérez." (La Nación, 29/01/06). 
A diferencia de Fallaci y Montero, Rivera no comienza con una caracterización explícita del personaje, sino con un hecho histórico que marcó su vida, la costarricense, y que probablemente explica su reelección presidencial en 2006: el Premio Nobel. Por decirlo de alguna manera, comienza con el "hecho noticioso", con el qué del quién. Además, de esta manera presenta otro elemento clave: la distancia de 20 años entre la primera presidencia y la segunda a la que entonces aspiraba: en muchos pasajes, la semblanza está escrita en términos de antes y ahora. Para escribir, junto con las conversaciones con Arias -escasas, según el texto-, Rivera se sirvió de la información recopilada al acompañarlo en sus giras proselitistas, de las conversaciones con asesores, viejos amigos y rivales políticos; todo, con el propósito de lograr un retrato del antiguo $y$ futuro presidente costarricense. $\mathrm{Y}$ en su cierre, nuevamente a diferencia de Fallaci y Montero, no hay una caracterización del personaje, pero sí una vuelta al origen de la semblanza, a la entrada: "Así, la figura de Óscar Arias se perfila como un cuerpo con dos cabezas que, si las encuestas no fallan, gobernará Costa Rica en los próximos cuatro años. "Somos para América un símbolo de paz y queremos ser símbolo de desarrollo", dijo Arias a los miembros de la academia sueca, hace ya veinte años. Todo indica que está punto de lograr una segunda oportunidad con la historia."

Un inmenso detalle: en las tres semblanzas presentadas, la entrada y el cierre correspondían a una perspectiva escogida por el periodista... Pero ninguna era la única posible. Cualquier otro entrevistador pudo asegurar, y en efecto hacerlo, que había encontrado quién es Henry Kissinger, y así comenzar y cerrar su semblanza. En lugar de la terquedad esencial de Beauvoir, una mirada más amigable pudo enfatizar en las primeras líneas su lugar como uno de los pilares del feminismo mundial, o cerrar con su larga historia de intelectual comprometida. Y en cuanto a Arias, pudo ser más complaciente y tratarlo en el primer párrafo como un gobernante para el futuro y no del pasado; o más agresivo y con alguna anécdota poner en evidencia su célebre vanidad.

En periodismo, la escritura de cada línea supone elegir una entre muchas perspectivas, incluso apegándose estrictamente a la información recopilada.

\subsection{Creación y verdad}

Al tratar la semblanza, Escobar y Leñero y Marín coinciden en el papel creativo del periodista: organizador de la información y responsable de otorgarle una presentación atractiva para el lector. En la semblanza, el periodista no busca la objetividad, lo que la opone a 
los convencionales discursos de "objetividad periodística" -muchas veces provenientes del mismo gremio periodístico-; es más, esta imposibilidad queda clara para el público cuando descubre un punto de vista o una jerarquía en la información.

Por supuesto, la entrevista de personalidad es un género periodístico y esto exige un estricto apego a la información recogida; pero dentro de esto y al igual que la crónica, es un texto que se roza con la literatura. Especialmente, porque supone construir un personaje: "Intentas darle una coherencia, ordenar el caos que es el mundo y que es una persona, insisto, sin alterar la realidad (...) Una intuición de ese diseño básico. Y eso, ¿qué es? Pues, eso es crear un personaje literario", explica Rosa Montero (cit. en Halperín, 283).

Esta creación supone una dificultad: no maniatar con un par de adjetivos a una personalidad compleja. En ocasiones, el personaje simplemente se le escapa al periodista: cuando parece que se acierta con una etiqueta, descubrimos algo que la contradice radicalmente. Un caso es el ya citado de la entrevista de Fallaci a Kissinger, cuya imposibilidad residía en el hermetismo del entrevistado; otro es el del encuentro con la exgobernante Indira Gandhi, de quien solo pudo afirmar: "Era, además, muchas otras cosas y, como Indira Gandhi, todas ellas en contraste entre sí. Cuanto más se le estudiaba, más confuso, más inseguro quedaba uno" (Fallaci, 200). En ambos casos, la opción escogida por la periodista italiana es la mejor, o al menos la más prudente: si tras la recopilación de información persiste la dificultad de "delimitar" al otro, lo mejor es hacer de ese aprieto una parte del texto, un elemento más para el juicio del lector. Y por supuesto, mostrar los infructuosos esfuerzos realizados para aproximarse a esa personalidad compleja: las preguntas, la descripción de gestos significativos o el contraste de opiniones.

Al crear este personaje, literario pero apegado a la realidad, emerge el problema de la verdad. Es un problema porque la principal fuente suelen ser las declaraciones del personaje, pero como bien sabemos, "las personas dicen y hacen cosas diferentes en distintas situaciones" y por tanto "no debe darse por sentado que lo que una persona dice en la entrevista es lo que esa persona cree $o$ dice en otras situaciones" (Sierra, 311). Otra vez, el jugoso texto de $E l$ duque en sus dominios brinda un buen ejemplo: la declaración que Marlon Brando hace varias veces de que "Solo el cuarenta por ciento de lo que digo es en serio" (Capote, 27). ¿Qué hacer con una fuente que miente? - ¿O con una que dice mentir?-. Puede argüirse que esta diferencia entre el decir y el hacer es ya un dato importante..., pues sí, y como tal es mejor exponerlo al lector: que la contradicción sea parte de la historia, que conozca las distintas versiones de los hechos. Dicho más claramente: al entrevistado le son lícitas las mentiras o imprecisiones, pero no al periodista. 
Generalmente una disciplina positivista, el periodismo persigue los hechos que sean cuantificables y verificables. Y su verdad, como la científica, tiene sus limitaciones, bien expuestas por el periodista argentino Daniel Ulanovsky: "Cualquier discurso que uno formule (...) implica una especie de desglosamiento, de fotografía parcial de la realidad. Incluso si yo te tomo una fotografia, yo no voy a figurar y nadie sabrá que estuve en esa mesa. La fotografía no es mentirosa, pero, al mismo tiempo, tampoco es cierta en un ciento por ciento" (cit. en Halperín, 266).

\subsection{Espíritu fair play}

Es irónico, pero con los años y como escritora de éxito que es (Un hombre, Carta a un niño que nunca nació), Fallaci pasó de entrevistadora a entrevistada; entonces, supo de la tiranía del undécimo mandamiento y declaró: "cada vez que una es entrevistada, vende su alma" (cit. en Halperín, 176). Pocas maneras tan exactas para retratar el terror de la fuente ante el periodista, ante su inmenso poder al entrevistar $\mathrm{y}$, todavía más, cuando redacta, porque no tiene oponentes materiales.

No es vano que Martínez Albertos recomienda, con marcado énfasis, "la necesidad de trabajar la entrevista con espíritu de elegancia moral, con fair play”. Según advierte, una entrevista puede estar colmada de pequeños actos difamatorios, muchas veces nacidos "del prurito del periodista por quedar ante el lector como un hombre agudo e inteligente, con cierto desprecio comparativo para el interlocutor" (Martínez Albertos, 112). El lucimiento que no logra durante la entrevista, el periodista irresponsable lo consigue en la redacción final del texto, que es la que conoce el público; en publicaciones de todo el mundo, incluida Costa Rica, es frecuente toparse con periodistas a quienes interesa más la pregunta que la respuesta o, en el caso de la semblanza, brindan prioridad a su narración frente a las declaraciones del entrevistado.

Nuevamente, hay un pero epistemológico y otro ético a este comportamiento. Epistemológico, porque la información que llega al lector está distorsionada, o disminuida, para dar cabida a los pavoneos del periodista. Y ético, porque es un irrespeto hacia el entrevistado (el Otro que se quiso aprehender), y hacia el lector, que no tiene una versión honesta de este personaje. En este sentido, Halperín recoge la sugerencia de Bill Kovach: "Cuando escribáis un artículo sobre alguien..., volved a leerlo, pero cambiando su nombre por el vuestro".

\section{Para cerrar...}

Todo género periodístico tiene sus dificultades, suponer superar escollos: esto es válido tanto para la nota informativa como para una serie de reportajes. En las anteriores páginas, fueron repasadas algunas de las de la entrevista de perfil, de personalidad o semblanza. 
A manera de resumen: ¿Qué es una semblanza? Según el diccionario, es una "descripción física o moral de una persona" (Larousse, 601); pues lo mismo es en el periodismo: un texto que busca retratar de una manera integral a una persona. Desde este artículo, una semblanza supone enfrentarse profesionalmente a las de por sí cotidianas dificultades de "aprehender al otro": saber de él, conocer su historia, sus motivos, sus valores y temores. Lograr una empatía; dejarse contagiar por la simpatía. Pero sin dejar de ser un buen periodista, con todo lo que esto significa.

Según se ha planteado, esta aprehensión ocurre en dos momentos: al enfrentarse al personaje (documentación, pero especialmente entrevistas) y al revivirlo en la escritura de un texto. Al encontrarse entrevistador y entrevistado, las dificultades tienen que ver con el rapport; se puede optar por una estrategia confrontadora, pero lo más recomendable es la cordialidad, que sea una conversación como cualquier otra, sin que esto suponga debilidad o un espíritu acrítico por parte del periodista. Esta cordialidad debe conseguirse sin abandonar un estado de alerta permanente, atenta al más mínimo detalle: desde las respuestas del entrevistado hasta la información que se descubre en el contexto.

Los valores y prejuicios del periodista pueden causar algunos problemas: no es recomendable ocultarlos -y mucho menos al lector-, pero tampoco alimentarlos. Y esto va en los dos sentidos: a favor y en contra del que será el protagonista de la semblanza. Posteriormente, al escribir, aumentan las dificultades éticas porque el periodista queda solo con el material recopilado -bueno, se le opone su conciencia-: puede malinterpretar, puede buscar su lucimiento frente al entrevistado. Es de esperar que un buen profesional sepa superar sin dificultad estos obstáculos.

Finalmente, en materia epistemológica la etapa de la escritura muestra al periodista el hecho de que los datos fríos son insuficientes para mostrar lo descubierto en el otro; por eso, recurre a la metáfora, a la analogía, incluso a la hipérbole. También esto puede ser un riesgo, si no se acierta con la figura literaria o si el placer de la creación le hace olvidar la obligación de informar.

\section{Referencias}

Alonso, L. E. (1999). "Sujeto y discurso: el lugar de la entrevista abierta en las prácticas de la sociología cualitativa”. En Delgado, J. M. y Gutiérrez, J. Métodos y técnicas cualitativas de la investigación en Ciencias Sociales. Síntesis. Madrid.

Bernstein, C.; Woodward, B. (1977). Todos los hombres del presidente. Argos. Barcelona.

Capote, T. (2000). "El duque en sus dominios”, en Retratos. Anagrama. Barcelona.

Escobar, F.; Martínez, M.; Vargas, O. (2001). El quehacer periodístico. Editorial Castro Madriz. San José.

Fallaci, O. (2000). Entrevista con la historia. Noguer. Barcelona. 
Halperín, J. (1995) La entrevista periodística. Intimidades de la conversación pública. Paidós. Buenos Aires. Kundera, M. (1992). La inmortalidad. RBA Editores. Barcelona.

Larousse (2001). Diccionario de la lengua española. Esencial. Larousse. México.

Leñero, V.; Marín, C. (1986). Manual de periodismo. Grijalbo. México.

Martínez Albertos, J. L. (s.f.) Redacción periodística. A. T. E. Barcelona.

Montero, R. (2003). "Voluntad de ser”, en Historias de mujeres. Punto de Lectura. Madrid.

Pujadas M., J. J. (1992). "Los usos del método biográfico". En Cuadernos metodológicos. No. 5. Centro de Investigaciones Sociológicas. Madrid.

Rivera, E. “Un candidato con dos cabezas”, en La Nación, 29 de enero del 2006.

Sánchez, J. F. (1997) La entrevista periodística: introducción práctica. EUNSA. Pamplona.

Sierra, F. (1995) "Función y sentido de la entrevista cualitativa en la investigación social”, en Galindo Cáceres, J. Técnicas de investigación en sociedad, cultura y comunicación. Addison Werley Longman y Consejo Nacional de la Cultura y las Artes. México.

\section{Nota acerca del autor}

\section{Bértold Salas Murillo}

Licenciado en Ciencias de la Comunicación Colectiva, actualmente es profesor de Apreciación de Cine, en la Escuela de Estudios Generales de la Universidad de Costa Rica, y asesor académico en la rectoría de la Universidad Nacional. Estudiante de los posgrados de Filosofía y de Artes con énfasis en Cinematografía, ambos de la Universidad de Costa Rica

Correo electrónico: bertold.salas@ucr.ac.cr 